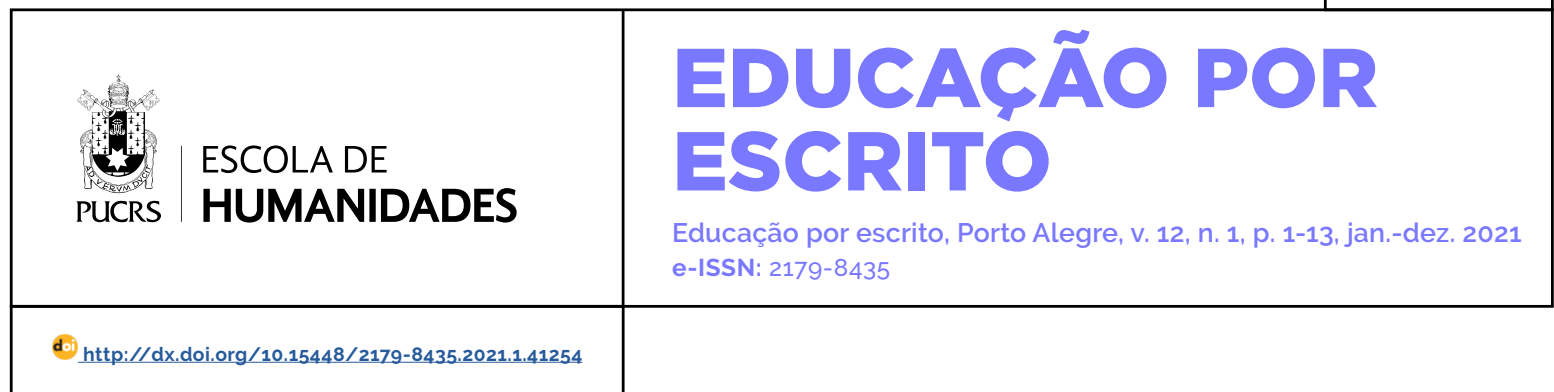

SEÇÃO: A FORMAÇÃO DE PROFESSORES E A EDUCAÇÃO INCLUSIVA: AVANÇOES, DESAFIOS E PERSPECTIVAS

\title{
As políticas de formação de professores e os desafios no fazer pedagógico na escola do campo do município de Placas (PA)
}

\author{
The policies of teacher training and the challenges in pedagogical doing in the school \\ of the field of the municipality of Placas (PA)
}

\section{Irlanda do Socorro de Oliveira Miléo ${ }^{1}$ \\ orcid.org/0000-0002-7075-6503 \\ irlanda@ufpa.br}

\section{Marcos Marques \\ Formigosa $^{1}$ \\ orcid.org/0000-0001-6279-1459 mformigosa@ufpa.br}

\section{Adayane Silva \\ de Souza ${ }^{2}$ \\ adayanesouza26@gmail.com}

Recebido em: 05/07/2021. Aprovado em: $12 / 11 / 2021$. Publicado em: 17/12/2021
Resumo: O objetivo da pesquisa foi identificar como os professores se posicionam em relação às políticas de formação dos docentes e se as formações que possuem possibilitam desenvolver práticas pedagógicas que contemplem a realidade das escolas do campo. Este estudo ocorreu mediante uma revisão bibliográfica e uma pesquisa de campo em uma escola municipal, situada na Rodovia BR 230 - Transamazônica, km 200, área rural de Placas (PA), onde a diretora, a coordenadora pedagógica e três docentes da referida escola responderam a um questionário, e os dados gerados foram analisados numa perspectiva qualitativa. A pesquisa aponta que devido à falta de oferta de cursos destinados aos professores do campo que contemplem seus distintos contextos, há o surgimento de inúmeros entraves para esse profissional desenvolver um bom trabalho, afetando assim, não só a qualidade profissional, mas a aprendizagem dos estudantes do campo. Além disso, acreditamos ser necessário fazer algumas reflexões a respeito das políticas de formação de professores no cenário brasileiro, pois embora percebamos que haja a manifestação de intenções quanto à formação inicial e continuada dos docentes na atualidade, é preciso considerar, de modo especial, aqueles que atuam nas escolas do campo, como forma de se ter uma educação efetivamente inclusiva para esses sujeitos.

Palavras-chave: Educação do Campo. Escolas Multisseriadas. Formação inicial. Formação Continuada.

Abstract: The aim of the research was to identify how teachers position themselves in relation to teacher education policies and whether the training they have makes it possible to develop pedagogical practices that contemplate the reality of the schools in the field. This study occurred through a bibliographic review and a field research in a municipal school, located on highway BR 230 - Transamazônica, km 200, rural area of Placas (PA), where the director, the pedagogical coordinator and three teachers of the said school answered a questionnaire, and the data generated were analyzed from a qualitative perspective. The research points out that due to the lack of offer of courses for teachers in the field that contemplate their different contexts, there is the emergence of numerous obstacles for this professional to develop a good work, thus affecting not only the professional quality, but the learning of the students of the field. In addition, we believe it is necessary to make some reflections about teacher education policies in the Brazilian scenario, because although we realize that there is a manifestation of intentions regarding the initial and continued training of teachers today, it is necessary to consider, in a special way, those who work in the schools of the field, as a way of having an effectively inclusive education for these subjects.

Keywords: Rural Education. Multiseriated Schools. Initial training. Continuing Education.

\section{(c) (1)}




\section{Introdução}

O texto em tela situa-se no campo das políticas de formação de professores das escolas do campo e reflete questões relacionadas às suas práticas pedagógicas. Trata-se de um tema que nos interessa discutir por apresentar situações que se manifestam nas diferentes escolas do campo da Mesorregião do Sudoeste do Pará e, de modo particular, em uma escola do campo da rede pública, na BR 230 - Rodovia Transamazônica, em Placas, Pará (PA).

Um dos aspectos que nos instigou a enveredar por essa temática decorre das diferentes situações que observamos no desenvolvimento das práticas pedagógicas realizadas no espaço escolar por meio dos Tempos Comunidades (TC) ${ }^{2}$ no âmbito do Curso de Licenciatura em Educação do Campo, ofertado pela Universidade Federal do Pará (UFPA), Campus de Altamira. Além dos TC, tivemos a oportunidade de acompanhar as ações docentes no cotidiano da sala de aula por ocasião das atividades de Estágio Supervisionado ( $T C \vee$ e VI) que nos permitiram compreender a dinâmica do planejamento, organização e implementação do trabalho pedagógico nos anos finais do Ensino Fundamental.

Na ocasião, apreendemos as professoras que atuavam naquela escola. Uma possuia Licenciatura em Pedagogia e a outra estava cursando Licenciatura em Educação do Campo (ênfase em Linguagens e Códigos) e enfrentavam muitos desafios em suas práticas pedagógicas, devido ao fato de não possuírem formação considerada apropriada para trabalhar com todas as disciplinas que compõem o quadro curricular desta etapa de ensino, uma vez que o Curso de Pedagogia ${ }^{3}$ habilita para a docência na Educação Infantil e os anos iniciais do Ensino Fundamental, enquanto que o Curso em Educação do Campo (ênfase em Linguagens e Códigos) possibilita a atuação no ensino de Língua Portuguesa nos anos finais do Ensino Fundamental e ensino médio. Além delas, percebemos o fato de muitos docentes naquele municipio ${ }^{4}$ não terem formação adequada - com licenciatura em área distinta e até mesmo com apenas o ensino médio - para lecionar disciplinas nos anos finais $\left(5^{\circ}\right.$ ao $9^{\circ}$ ) do Ensino Fundamental nas escolas do campo, conforme preconizado pela Lei de Diretrizes e Bases da Educação (LDB) - Lei n 9.394/1996 (Art. 62 e Art.87, § 41) de que a etapa da Educação Básica deveria ser ministrada por professores formados em nivel de graduação, e os docentes dos anos finais do Ensino Fundamental com licenciaturas em áreas especificas de conhecimento para atender disciplinas que compõem o desenho curricular.

Assim, as questões que subsidiaram nosso estudo buscaram refletir quais os desafios para a atuação docente nas escolas no campo diante das demandas dos povos que vivem e trabalham no campo e se a formação que esses profissionais possuem lhes permite desenvolver ações pedagógicas em diferentes áreas do conhecimento sob o ponto de vista de suas necessidades, dificuldades e anseios, tendo como cenário o contexto sociocultural das escolas do campo.

O objetivo central que norteou essa investigação foi identificar como os docentes se posicionam em relação às politicas de formação dos docentes e se as formações que possuem possibilitam desenvolver práticas pedagógicas que contemplem a realidade das escolas do campo no municipio de Placas (PA). Com os objetivos especificos procuramos examinar a existência ou não de formações especificas à educação do campo promovidas pela Secretaria Municipal de Educação (SEMED) de Placas (PA) e identificar as possiveis dificuldades enfrentadas pelos docentes em decorrência de uma formação não adequada às disciplinas que lecionam nos anos finais do Ensino Fundamental.

Para alcançar os objetivos pretendidos, desenvolvemos uma pesquisa qualitativa compreendida a partir de Chizzotti (2006). Este estudo ocorreu mediante uma revisão bibliográfica e uma

\footnotetext{
O curso é composto por oito TC, distribuidos nos oito semestres letivos.

Resolução CNE/CP nº 01 de 15 de maio de 2006

Essa situação também foi observada em outros municipios da Transamazônica em que temos turmas do Curso de Licenciatura em Educação do Campo, como Uruará, Medicilândia, Brasil Novo, Anapu e Pacajá.
} 
pesquisa de campo, e teve como lócus a Escola Municipal de Ensino Fundamental Getúlio Vargas, situada na Rodovia BR 230 - Transamazônica km 200, Vicinal lote 10 norte - Comunidade Terra prometida, área rural do Município de Placas (PA) e foi desenvolvida no decorrer dos TC II e III (2017) e dos Estágios Supervisionados I e II (2018 e 2019), periodo em ocorreram as aplicações dos questionários. O levantamento de dados foi realizado por meio de questionário direcionado à diretora, à coordenadora pedagógica e três docentes da referida escola.

\section{As políticas educacionais para a formação do educador do campo}

A formação do professor no contexto brasileiro, como aponta Saviani (2009) ao analisar seu percurso histórico, foi ofertada, inicialmente, no âmbito das Escolas Normais de nível secundário, em cursos especificos com objetivo de formar professores para o ensino das "primeiras letras", como estratégia para operacionalizar o ensino escolarizado em atendimento às demandas sociais, mas sem uma organização que promovesse práticas escolares de qualidade (GATTI; BARRETO; ANDRE, 2011). No campo, parte dessa formação se materializa mediante a proposta de uma instituição para formação específica dirigida aos professores do meio rural, no âmbito das escolas Normais Rurais, expressando a visão que representava a forma como concebiam as populações do campo, pois, como afirma Leite (2005, p. 14), a educação rural no cenário brasileiro era relegada a um modelo que traduzia a ideologia religiosa concebida pelos jesuítas, destinada a uma elite, constituida por ideários da oligarquia agrárias "[...] conhecida popularmente na expressão: 'gente da roça não carece de estudos. Isso é coisa de gente da cidade'".

As políticas de formação docente, a partir da década de 1990, passam por transformações articuladas às proposições de organismos internacionais, com destaque para o Banco Mundial, sendo essas, elaboradas em consonância com diretrizes voltadas ao desenvolvimento econômico dos países periféricos, a exemplo do Brasil.
Pautava-se em movimento educacional orientado pela satisfação das necessidades básicas da aprendizagem, para formar pessoas competentes visando atender com qualidade as exigências do mercado de trabalho. De acordo com Veiga e Viana (2010), o eixo condutor dessa mudança foi a aprovação da LDB - Lei nº 9.394/96, em decorrência de estabelecer o perfil de um professor com curso superior para atuar na educação básica "preparado para trabalhar com uma nova concepção de currículo, de avaliação e de gestão" (VEIGA; VIANA, 2010, p. 16). As autoras consideram ainda que o processo formativo desse profissional precisa ir além dessas determinações formalistas e pragmáticas que silenciam os profissionais da educação, particularmente, aqueles que exercem o magistério nas escolas do campo. Enfatizam ainda a necessidade de uma base teórica e epistemológica consistente como estratégia de superar as atuais propostas formativas neotecnicistas, de modo a subsidiar ações didático-pedagógicas que auxiliem o professor a avançar na relação com o saber diante da diversidade sociocultural encontrada nesse território (SANTANA, 2014).

Esse entendimento é compartilhado com o posicionamento de Sheibe (2010) ao defender que a formação docente precisa ser organizada a partir de um conjunto de conhecimentos e saberes articulados a uma formação política, cultural, dialética, capaz de transgredir o conteúdo pedagógico fundamentado em uma racionalidade técnica-pragmática e prescritiva do trabalho docente. Esses destaques dados pela autora são também percebidos por Arroyo (2007, p. 158) quando afirma que:

A história nos mostra que não temos uma tradição nem na formulação de políticas públicas, nem no pensamento e na prática de formação de profissionais da educação que focalize a educação do campo e a formação de educadores do campo como preocupação legítima.

Ao trazermos questões referentes às características e problemas da formação de professores no Brasil, Gatti (2010) destaca que poucos foram os avanços significativos na trajetória dos mo- 
delos de formação propostos aos professores. Após analisar projetos pedagógicos de diferentes cursos de licenciatura de instituições públicas e privadas das cinco regiões do país, a autora indica um panorama desolador a respeito das condições que esses cursos apresentam ao evidenciar a centralidade no aprendizado por meio de uma organização curricular enciclopédica, limitada à referência superficial aos estudos referentes aos sistemas educacionais; trazem ainda a abordagem de disciplinas teóricas e práticas desconexas aos conteúdos de ensino da educação básica, abordados de modo superficial, projetando, desse modo, uma formação pulverizada e desarticulada da educação básica. Esses aspectos impõem a necessidade urgente de novas alterações na formação docente com a finalidade de redimensionar o trabalho docente por meio de ações formativas que superem essas tendências pragmáticas e tecnicistas, pois, "Até agora, a formação para o magistério esteve dominada, sobretudo, pelos conhecimentos disciplinares [...], sem nenhuma conexão com a ação profissional" (TARDIF, 2006, p. 23).

Ao considerarmos as orientações expressas na atual LDB e nas Diretrizes Curriculares Nacionais Gerais para a Educação Básica - DCN (BRASIL, [2013]), quando estabelece no Artigo $2^{\circ}$ seus objetivos, é possivel perceber que muito ainda preciso ser feito pelos governantes para avançar nas propostas formativas para os povos do campo:

I - sistematizar os princípios e diretrizes gerais da Educação Básica contidos na Constituição, na LDB e demais dispositivos legais, traduzindo-os em orientações que contribuam para assegurar a formação básica comum nacional, tendo como foco os sujeitos que dão vida ao curriculo e à escola;

II - estimular a reflexão crítica e propositiva que deve subsidiar a formulação, execução e avaliação do projeto político-pedagógico da escola de Educação Básica;

III - orientar os cursos de formação inicial e continuada de profissionais - docentes, técnicos, funcionários - da Educação Básica, os sistemas educativos dos diferentes entes federados e as escolas que os integram, indistintamente da rede a que pertençam.

Os objetivos da DCN propostos para a Educação Básica evidenciam uma preocupação com a necessidade de elaboração de políticas e programas voltados à formação docente, de modo a proporcionar que esses profissionais possam dispor de qualificação para desenvolver seu fazer pedagógico, mas ainda falta avançar na incorporação das particularidades que essas formações precisam proporcionar aos professores que atuam na educação escolar indígena, quilombola e do campo, de maneira mais pontual e política, pois como nos diz Caldart (2004, p.150), a educação do campo "como direito, não pode ser tratada como serviço nem como política compensatória; muito menos como mercadoria".

Os esforços hoje empreendidos em relação à formação dos professores que atuam na educação do campo vêm sendo reconhecidos recentemente pelo Estado, como destacam Gatti, Barreto e André (2011), sendo estes, resultado de um processo de mobilizações históricas dos diversos coletivos sociais que defendem o direito à educação das populações que vivem e trabalham no campo. Essas lutas colocaram a educação do campo no centro das discussões teóricas e politicas, o que impulsionou questionamentos acerca do modelo de educação rural conservador, com a visão do meio urbano como lugar de progresso e do meio rural lugar de atraso, trazendo à tona o conceito de campo como território, ou seja, "onde se realizam as diversas formas de organização do campesinato e também as formas de organização da agricultura capitalista, denominada de agronegócio" (FERNANDES, 2006, p. 28).

Para assegurar a concretização do direito a uma educação de qualidade aos povos do campo, o Conselho Nacional de Educação aprova a Resolução no 1/2002 - CNE/CEB, que institui as Diretrizes Operacionais para a Educação Básica das Escolas do Campo (BRASIL, 2002). A ênfase no exercício da docência é apresentada no Artigo 12 , 
ao estabelecer que o sistema de ensino municipal ou estadual deverá assegurar formação inicial em curso de licenciatura àqueles profissionais que ainda não possuam o curso normal (magistério) e superior, prevendo como qualificação mínima para o exercício da docência na Educação Infantil e nos anos iniciais do Ensino Fundamental o curso de formação de professores em Nivel Médio, na modalidade Normal, atendendo o disposto na LDB (BRASIL, 1996). Recomenda ainda aos sistemas de ensino, no Artigo 13, a observância no processo de normatização da formação docente nas escolas do campo dos seguintes componentes:

I - estudos a respeito da diversidade e o efetivo protagonismo das crianças, dos jovens e dos adultos do campo na construção da qualidade social da vida individual e coletiva da região, do pais e do mundo:

II - propostas pedagógicas que valorizem, na organização do ensino, a diversidade cultural e os processos de interação e transformação do campo, a gestão democrática, o acesso ao avanço científico e tecnológico e respectivas contribuições para a melhoria das condições de vida e a fidelidade aos principios éticos que norteiam a convivência solidária e colaborativa nas sociedades democráticas (BRASIL, [2002]).

Caldart (2004) considera que essas conquistas legais resultaram das proposições elaboradas na I e na || Conferência Nacional Por uma Educação Básica do Campo, em 1988 e 2004, respectivamente, possibilitando construção dos ideais dos diferentes sujeitos envolvidos nesse processo. Munarin (2011, p. 10), por sua vez, afirma que a defesa por uma educação diferenciada articulada à cultura, ao jeito de viver e produzir e a autonomia dos camponeses é referenciada por "uma concepção de educação forjada a partir da luta pela terra e por políticas públicas empreendidas pelos movimentos sociais e organizações sociais do campo".

A criação do Decreto $n^{\circ}$ 7.352/2010, que dispõe sobre a Política Nacional de Educação do Campo e sobre o Programa Nacional de Educação na Reforma Agrária (PRONERA), deu novos rumos à questão da formação de professores das escolas do campo. Além de detalhar seus objetivos e natureza dos projetos a serem apoiados, apresenta os principios a serem referenciados no âmbito da gestão do programa e de fontes de financiamento, em conformidade com a realidade local e a diversidade das populações do campo. Quanto à política de Educação Superior do Campo expressa no referido Decreto, foi determinante para a ampliação das oportunidades de qualificação da Educação Básica pela via da Educação Superior dirigida às populações do campo, preconizando no Artigo $2^{\circ}$ (inciso III) a importância do desenvolvimento das "[...]políticas de formação de profissionais da educação para o atendimento da especificidade das escolas do campo [...]" (BRASIL, [2010]), onde se insere a Licenciatura em Educação do Campo. Outro ponto que destacamos é autonomia pedagógica e metodológica possibilitada aos cursos de ensino superior, cuja formação a ser proporcionada deve estar, conforme consta no Artigo $5^{\circ}$, $\S 2^{\circ}$ do supracitado Decreto "[...] de acordo com metodologias adequadas, inclusive a pedagogia da alternância, e sem prejuizo de outras que atendam às especificidades da Educação do Campo e por meio de atividades de ensino, pesquisa e extensão" (BRASIL, [2010]).

O reconhecimento da pedagogia da alternância como metodologia no processo de formação de professores para as escolas de Educação Básica do Campo possibilitou aos cursos organizarem suas propostas tomando como ponto de partida o ensino inter/transdisciplinar, com Tempo Universidade (TU) e Tempo Comunidade. O Decreto $n^{\circ}$ 7.352/2010 sinaliza para a garantia do acesso e permanência dos camponeses em um curso de formação superior quando consideramos a demografia e a dimensão territorial do Brasil, de modo particular, as condições de infraestrutura de estradas e transporte da nossa região da Transamazônica e do Xingu.

\section{A Escola do Campo e seus impasses quanto ao processo educacional}

Com a intenção de entender como a SEMED de Placas (PA) organiza seu quadro de professores, inicialmente, realizamos um levantamento sobre o número de professores que atuam nas escolas do campo nos anos iniciais e finais 
do Ensino Fundamental, a área de formação e disciplina que eles ministram. De acordo com o levantamento, no ano de 2018 havia um total de 112 educadores distribuidos em 55 unidades de ensino no município. Como área de formação no ensino superior foram detectadas: Pedagogia, Geografia, Matemática, Letras com habilitação em Lingua Portuguesa, Letras com habilitação em Lingua Inglesa, Licenciatura em Educação do Campo com habilitação em Linguagens e Códigos, Ciências Sociais, Biologia, História e Educação Física incompleta e, alguns professores, somente com o ensino médio.

A maioria desses profissionais trabalham com todas as disciplinas em uma determinada turma, e as demais disciplinas distribuidas de acordo com a necessidade de cada escola. Essa forma de a SEMED organizar a lotação dos professores concorre para que muitos deles ministrem disciplinas diferentes sem que tenham formação adequada para trabalhar com as mesmas, evidenciando uma falta de investimento na educação e na formação de educadores do campo que compromete a própria concepção de campo, ao mesmo tempo que promove uma desvalorização do trabalho docente à medida que coloca os professores sob a égide do mandonismo do gestor municipal.

Esse problema da escassez de professores com formação adequada nas escolas do campo denuncia tanto o tratamento histórico dado à educação do campo quanto a insuficiência de politicas educacionais especificas à garantia de uma educação do campo de qualidade em todas as regiões brasileiras (ARROYO; CALDART; MOLINA, 2009; FERNANDES, 2006; CALDART, 2008). No relatório Final da Educação da Reforma Agrária elaborado pelo Instituto de Estudos e Pesquisas Educacionais (INEP) no ano de 2005. os dados assinalam que "[...]na quase totalidade dos níveis/modalidades de ensino existentes, prevalece a existência de uma proporção elevada de escolas com professores formados no ensino médio magistério" (BRASIL, 2005, p. 92).

Outro documento, que apresenta uma pesquisa realizada também pelo INEP denominada "Panorama da Educação do Campo", evidencia que nas séries iniciais do Ensino Fundamental ( $1^{\mathrm{a}}$ a $4^{\mathrm{a}}$ série) somente $21,6 \%$ dos docentes das escolas do campo possuiam formação superior, enquanto nas escolas da cidade esse contingente totalizava $56,4 \%$ dos professores. Esse documento ainda destaca a presença de 6.931 funções docentes sendo desenvolvidas por professores que possuem o Ensino Fundamental, não dispondo, portanto, "[...] da habilitação mínima para o desempenho de suas atividades. A maioria desses professores leigos atua nas Regiões Nordeste e Norte" (INEP, 2006, p. 33), contrariando o disposto na LDB n 9394/96, ao mesmo tempo que revela a ineficiência do Estado em viabilizar uma política educacional que atenda as especificidades socioculturais dos povos do campo. Sobre essa questão, Arroyo (2007, p. 170) enfatiza que:

A falta de politicas de formação de educadores e educadoras tem por base a ausência de uma política pública específica de educação ou o não reconhecimento do direito à educação básica da infância, adolescência e juventude do campo.

O próprio Ministério da Educação (MEC) reconhece que a preocupação com a formação dos professores para o campo é inexistente na história da educação brasileira, uma vez a tendência foi seguir o modelo urbano como parâmetro para elaborar as experiências e projetos voltados aos camponeses, reproduzindo também as condições precárias de trabalho e baixo salário:

\begin{abstract}
[...] as condições de trabalho dos profissionais do magistério permanecem precárias. No caso específico da área rural, além da baixa qualificação e dos salários inferiores aos da zona urbana, eles enfrentam, entre outros problemas, sobrecarga de trabalho, alta rotatividade e dificuldade de acesso à escola, em função das condições das estradas e da falta de ajuda de custo para a locomoção (BRASIL, 2007, p. 33).
\end{abstract}

Em relação à pesquisa de campo, a EMEF Getúlio Vargas teve sua organização iniciada por volta de 1976, com seis familias vindas do Estado do Maranhão e de outros estados brasileiros durante o processo de colonização da BR 230 - Rodovia Transamazônica. O órgão federal responsável pela administração dos Programas Integrados de Colonização (PIC) na região de 
Altamira foi o Instituto Nacional de Colonização e Reforma Agrária (INCRA), responsável por todo o processo de assentamento dessas famílias aqui na região. A referida escola teve sua primeira construção em madeira em um lote comunitário doado por um morador do local no ano de 1986. Atualmente, é uma escola anexa da Escola MEC/ SEDUC KM 200-A e possui um prédio novo em alvenaria, com dois banheiros, duas salas de aula, uma secretaria e uma cozinha. Possui o Conselho Escolar que ajuda no acompanhamento das práticas escolares. O corpo docente é composto por profissionais com nivel superior e médio; alguns são concursados e outros são temporários. A professora mais antiga da escola exerce o magistério desde o ano de 1997.

Quanto aos docentes ${ }^{5}$ que participaram desse estudo, possuem experiência significativa no exercício do magistério na educação básica, principalmente nas turmas dos anos finais do Ensino Fundamental das escolas do campo. 0 professor Jorge tem formação inicial em Ciências Sociais e Matemática, possui pós-graduação em Gestão Escolar e Orientação em Matemática; trabalha com o ensino de matemática e ciências da natureza há 10 anos. A professora Mariana é Pedagoga e trabalha nos anos iniciais do Ensino Fundamental; atua em escolas do campo há oito anos. A professora Patrícia possui formação em Licenciatura Interdisciplinar em Educação do Campo (ênfase em Linguagens e Códigos), ministra as disciplinas de língua portuguesa, educação física e matemática; trabalha na escola Getúlio Vargas há quase sete anos.

Em relação à equipe pedagógica, ela pertence à Escola MEC/SEDUC KM 200-A, por ser a escola polo e acompanha as atividades de oito instituições de ensino anexas - como é o caso da escola Getúlio Vargas. É composta pela Coordenadora Pedagógica Amanda, que tem formação em Pedagogia e Ciências Naturais e há 18 anos atua na educação; e pela Diretora Bruna, formada em Letras - Lingua Portuguesa e Literatura Brasileira, com pós-graduação em Gestão Escolare já trabalha há 22 anos no magistério.

\section{Concepções acerca das políticas de formação de professores e de suas práticas pedagógicas}

Buscando entender como os docentes se veem no processo educativo das escolas do campo, perguntamos aos mesmos como percebem as políticas de formação de professores atuais e sua relação com as demandas educativas dos povos do campo. Suas respostas convergem para o entendimento da necessidade de haver formações diferenciadas que possibilitem aos educadores uma qualificação voltada às demandas locais, no sentido de superar a ausência de formações e de investimento na capacitação dos docentes, como foi destacado pelo Professor Jorge: "Uma educação de qualificação do educador, mas por outro lado, mais apoio que falta para os profissionais do lado do governo" (Professor Jorge, informação verbal). ${ }^{6}$ O depoimento da Professora Mariana destaca a importância da formação, pois "O professor sempre necessita estar em formação, pois é algo necessário para sua profissão, precisa sempre estar atualizado" (Professora Mariana, informação verbal).7 Para a Coordenadora Pedagógica Amada, essas formações representam "Um incentivo aos filhos de agricultores, porém, sem muita importância para gestores" (Coordenadora Pedagógica Amanda, informação verbal). ${ }^{8}$

Nesse debate, Fernandes (2006) considera que os avanços que marcam mudanças no cenário educacional brasileiro convergem para as transformações que foram se concretizando na forma de conceber a educação no e do campo, possibilitando o reconhecimento que as pessoas que vivem e trabalham nesse território também têm direito a uma educação diferenciada, não

\footnotetext{
Destacamos que os nomes dos participantes da pesquisa são fictícios

Depoimento do Professor Jorge, concedido à pesquisadora Adayane, em entrevista no decorrer do Estágio Supervisionado I, na cidade Placas, PA, Brasil, no dia 18 de outubro de 2018.

Depoimento da Professora Mariana, concedido à pesquisadora Adayane, em entrevista no decorrer do Estágio Supervisionado I, na cidade Placas, PA, Brasil, no dia 24 de outubro de 2018.

8 Depoimento da Coordenadora Pedagógica Amanda, concedido à pesquisadora Adayane, em entrevista no decorrer do Estágio Supervisionado II, na cidade Placas, PA, Brasil, no dia 21 de maio de 2019.
} 
podendo mais ficar dependentes do modelo educativo das escolas da cidade.

Ao perguntarmos aos participantes qual o conhecimento que possuem sobre as politicas e programas educacionais voltados para as escolas do campo, estes responderam:

Conhecimento sobre o plano de ensino com todos os professores e programas do governo federal para a formação de professores da área que atuam (Prof. Jorge, informação verbal)9.

O que se pode perceber é que há ainda uma grande necessidade de formação especifica, voltada principalmente para os professores que atuam em escolas do campo. Mesmo havendo a oferta de curso do nivel superior ofertado para graduação, "Educação do Campo", há ainda profissional no campo atuando em sala de aula apenas com o nivel médio (alguns com formação no (EPA), sendo preciso ainda mais investimento na educação no nivel superior, para formação inicial e continuada e outras formações que auxiliem os profissionais em sala de aula (Profa. Mariana, informação verbal). ${ }^{10}$

o conhecimento que considero ter é advindo de minha formação por meio do curso Educação do Campo, pela qual estudamos as diretrizes Curriculares da Educação do Campo (Profa. Patrícia, informação verbal).11

As respostas dos professores evidenciam algumas informações a respeito da existência de políticas de formação elaboradas de acordo com orientações legais para formar docentes especificamente para a educação do campo. Embora reconheçam que podem trazer inovações nas escolas do campo, há ainda a necessidade de pensar em formações continuadas também para os professores que atuam nesse contexto. Cardalt (2011) apresenta questões que precisam ser consideradas quando o assunto é formação de professores e sua articulação à educação do e no campo, à medida que a formação por área, característica das Licenciaturas em Educação do Campo, evidencia potencialidades por meio de duas convicções que devem ser devidamente explicitadas e divulgadas para possibilitar maior entendimento da sociedade no que diz respeito à docência por área de conhecimento:
A primeira convicção [...] é apenas uma das ferramentas escolhidas (dentro das circunstâncias históricas determinadas) para desenvolver uma das dimensões (a da docência) do projeto de formação de educadores que dê conta de pensar os caminhos da transformação da escola [...]. A segunda concepção é a de que a discussão ou a elaboração especifica sobre a formação para a docência por área deve ser ancorada em um projeto de transformação da forma escolar atual, visando contribuir especificamente no pensar de dois de seus aspectos fundamentais, que são: a alteração da lógica de constituição do plano de estudos, visando a desfragmentação curricular pela construção de um vínculo mais orgânico entre o estudo que se faz dentro da escola e as questões da vida dos seus sujeitos concretos; e a reorganização do trabalho docente, objetivando superar a cultura do trabalho individual $e$ isolado dos professores (CALDART, 2011, p. 97).

Esses esclarecimentos precisam ser feitos como estratégia de provocar debates substanciais, pois a autora entende que além dessa proposta formativa por área contribuir para qualificar as práticas pedagógicas a partir dos fundamentos do projeto da educação do/no campo, também possibilita a própria manutenção da escola do campo, ou seja, de qualificar os argumentos dos segmentos sociais que defendem as escolas do campo diante da política de fechamento de escolas por parte dos governos sob a alegação de inviabilidade gerada pela dispersão populacional na zona rural, que reflete em números reduzidos de alunos em cada série/ano, demandando um "gasto desnecessário". Outro aspecto destacado por Caldart (2011) é referente a possibilidade que esse tipo de organização formativa por área viabiliza ao substituir o modelo de uma escola organizada por um professor por disciplina; uma outra perspectiva de organização pedagógica mediada agora por uma equipe docente trabalhando com o conjunto das disciplinas de cada área do conhecimento.

A diretora escolar demonstrou não ter informações a respeito dessas políticas, além de associar a temática ao que é proposto pelo municipio ao responder o seguinte: "Em nosso currículo ainda

\footnotetext{
9 Depoimento do Prof. Jorge concedido à pesquisadora Adayane, em entrevista no decorrer do Estágio Supervisionado I, na cidade Placas, PA, Brasil, no dia 18 de outubro do ano de 2018.

10 Depoimento da Professora Mariana concedido à pesquisadora Adayane, em entrevista no decorrer do Estágio Supervisionado II, na cidade Placas, PA, Brasil, no dia 24 de outubro do ano de 2019.

11 Depoimento da Professora Patrícia concedido à pesquisadora Adayane, em entrevista no decorrer do Estágio Supervisionado II, na cidade Placas, PA, Brasil, no dia 29 de abril de 2019.
} 
não temos programas voltado para as escolas do campo" (Diretora da Escola Bruna, informação verbal). ${ }^{12}$ Essa profissional precisa compreender que a questão da formação dos professores para as escolas do campo pressupõe desenvolver articulações que vão além de incorporações no currículo. Trata-se de um tema que demanda refletir outras dimensões referentes à produção da vida no campo e ela, como diretora de escola situada no meio rural, demanda perspectivar a escola do/no campo, não somente como questões geográficas, sobretudo, como estratégia de vincular as práticas e a organização do trabalho escolar às necessidades e à solução dos problemas da comunidade camponesa. E ela, ocupando a gestão escolar, é responsável por mediar esse debate no projeto pedagógico dessa comunidade.

Indagamos também a respeito das formações que os docentes possuem, se consideram ser suficientes para atuar nas escolas do campo e desenvolver práticas pedagógicas pertinentes ao processo formativo dos estudantes camponeses. Ao se posicionar sobre essa questão, a Diretora da Escola, Bruna, entende que os professores precisam "[...] adaptar-se ao estudo do campo" (Informação verbal ${ }^{13}$ inserindo em suas metodologias conteúdos que contemplem as especificidades locais. A Coordenadora Pedagógica, Amanda, argumenta que os professores precisam buscar melhorar suas práticas, "[...] uma vez que o saber é individual e a busca pelo mesmo depende do esforço de cada um" (informação verbal). ${ }^{14}$ Esses posicionamentos centram-se em uma visão individualista do trabalho docente, ao contrário do que Arroyo (2007, 2011) e Munarim e Locks (2012) defendem como um trabalho coletivo de partilha e planejamento coletivo.
À essa questão, os professores se manifestaram da seguinte forma:

\begin{abstract}
Sim, os professores quase todos têm formação nas áreas que atuam e quem ainda não tem formação está concluindo os estudos (Prof. Jorge, informação verbal). ${ }^{15}$

Em nivel de estudo, sim, mas é necessário principalmente o conhecimento da vivência geral da comunidade na qual a escola está inserida, vivência, a convivência e a experiência dos alunos (Profa. Mariana, informação verbal). ${ }^{16}$

Não considero suficiente, pois muitas vezes encontramos dificuldades, situações que fogem do nosso conhecimento intelectual (Profa. Patricia, informação verbal). ${ }^{17}$
\end{abstract}

Refletindo sobre as especificidades do trabalho docente quanto à sua qualificação e os desafios que thes são colocados, Tardif (2007) observa que os elementos que compõem a rotina desse profissional vão além das tarefas que dizem respeito à prática pedagógica, como o planejamento das aulas, o acompanhamento da aprendizagem dos alunos e, por ser uma ação complexa. Segundo o autor.

[...] o trabalho cotidiano do professor é um ato que não apenas engloba a prática pedagógica, mas também estrutura organizacional, pressupostos, valores e condições de trabalho, método, organização e âmbito das atividades, organização do tempo e do espaço [...] (TARDIF. 2007, p. 121).

Essa compreensão remete à promoção do desenvolvimento de atividades articuladas ao exercício da práxis, no sentido de envolver a dialeticidade da teoria e prática em um mesmo movimento, conforme enfatiza Caldart (2011, p. 104) ao considerar que o desafio da formação do/a educador/a do campo:

\footnotetext{
12 Depoimento da Diretora da Escola Bruna, concedido à pesquisadora Adayane, em entrevista no decorrer do Estágio Supervisionado II. na cidade Placas, PA, Brasil, no dia 5 de junho de 2019.

13 Depoimento da Diretora da Escola Bruna, concedido à pesquisadora Adayane, em entrevista no decorrer do Estágio Supervisionado II, na cidade Placas, PA, Brasil, no dia 5, junho de 2019.

14 Depoimento da Coordenadora Pedagógica Amanda concedido à pesquisadora Adayane, em entrevista no decorrer do Estágio Supervisionado II, na cidade Placas, PA, Brasil, no dia 21 de maio de 2019.

15 Depoimento do Prof. Jorge concedido à pesquisadora Adayane, em entrevista no decorrer do Estágio Supervisionado I, na cidade Placas, PA, Brasil, no dia 18 de outubro de 2018.

16 Depoimento da Profa. Mariana concedido à pesquisadora Adayane, em entrevista no decorrer do Estágio Supervisionado I, na cidade Placas, PA, Brasil, no dia 24 de outubro de 2018.

17 Depoimento da Profa. Patrícia concedido à pesquisadora Adayane, em entrevista no decorrer do Estágio Supervisionado ll, na cidade Placas, PA, Brasil, no dia 29 de abril de 2019.
} 
É o de construir estratégias pedagógicas que materializem dentro do próprio curso o exercício da práxis, ou seja, que permitam o educador aprender a juntar teoria e prática em um mesmo movimento que é o da transformação da realidade (do mundo) e de sua autotransformação humana, de modo que esteja preparado para ajudar a desencadear esse mesmo movimento nos processos educativos que participa.

Isso significar dizer que a prática pedagógica do professor do campo não se situa somente nos conhecimentos disciplinares, mas pressupõe incorporar no currículo a dinâmica de produção do conhecimento tradicional que as familias camponesas possuem e que são naturalizados e invisibilizados nas propostas pedagógicas das escolas, passando despercebido pelos docentes e pela gestão escolar, gerando situações de inferiorização e desqualificação de todas as ordens inimagináveis na formação do educando e do próprio educador, conforme destaca Arroyo (2007).

Por isso, perguntamos aos participantes quais seriam as possiveis dificuldades que enfrentam em decorrência da escassez de formações específicas voltadas para quem atua na educação do campo. Os docentes se posicionaram das seguintes formas:

A maior dificuldade enfrentada são salas superlotadas de alunos e o ambiente escolar inadequado [...]. Outro problema que os professores enfrentam são escolas que têm multisseriado, ou seja, muitas séries juntas, do pré de quatro anos até o quinto, ou no ensino fundamental maior (Prof. Jorge, informação verbal). ${ }^{18}$

A falta de material didático (específico para as escolas do campo), o currículo unificado (campo/ cidade), onde os conteúdos são os mesmos para o campo e a cidade durante todo o ano letivo (Profa. Mariana, informação verbal). ${ }^{19}$

Uma das principais dificuldades encontrada é ter que ministrar disciplina que não pertence ao nosso campo de formação, isso em decorrência da carga horária que é mínima ou pela ausência de profissionais especificos. Outra dificuldade encontrada é ter que trabalhar um currículo de escolas seriadas, no modelo de escolas multisseriadas, situação muito comum nas escolas do campo. A existência de escolas multisseriadas com o uso de um currículo descontextualizado, sendo que as escolas do campo são de uma realidade totalmente diferente, onde é comum professores atuarem em áreas distintas a da sua formação e, que por ventura, tem um currículo a ser seguido, habilidades a serem alcançadas de modo que os alunos possam realizar as avaliações unificadas que o município passou a adotar o sistema. Então, creio que se já tínhamos dificuldades, agora nos recai mais uma exigência sem que tenhamos qualquer que seja o respaldo necessário (Profa. Patrícia, informação verbal). ${ }^{20}$

A partir das falas dos docentes, percebemos o quão distantes ainda se encontram as escolas do campo da construção de um projeto de educação que, de fato, possibilite compreender a realidade do campo e superar as contradições que marcam a organização do tempo e espaço das escolas do campo, na perspectiva de esta assegurar a identidade cultural das populações que moram e trabalham no campo, como observa Caldart (2004).

Quanto aos posicionamentos das profissionais da educação que respondem pela gestão da escola investigada, evidenciam um desconhecimento a respeito dos anseios e dificuldades do trabalho dos professores, uma vez que consideram que "São poucas as dificuldades, porque temos muitos profissionais formados ou em formação, e a clientela é pouca para atender" disse a Coordenadora Pedagógica Amanda. A percepção da Diretora Escolar Bruna não foi muito diferente: "Pelos esforços dos educadores, acredito que nenhum, tendo em vista que os mesmos buscam amenizarem essa situação agregando a sua atuação em sala com conteúdos que contemplem a realidade do aluno do campo" (Informação verbal). ${ }^{21}$

Os relatos aqui expostos evidenciam o quanto é necessário a equipe da gestão escolar e da própria SEMED conhecer as particularidades das escolas do campo e do coletivo de sujeitos que dão vida a essa instituição e ao próprio ato educativo, de modo a investir mais em formação continuada. Segundo Fernandes, Cerioli e Caldart

\footnotetext{
18 Depoimento do Prof. Jorge concedido à pesquisadora Adayane, em entrevista no decorrer do Estágio Supervisionado I, na cidade Placas, PA, Brasil, no dia 18 de outubro de 2018

19 Depoimento da Profa. Mariana à pesquisadora Adayane, em entrevista no decorrer do Estágio Supervisionado I, na cidade Placas, PA Brasil, no dia 24 de outubro de 2018.

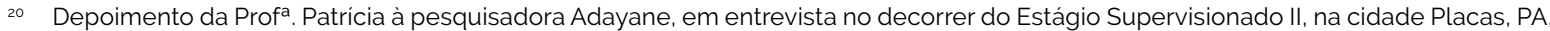
Brasil, no dia 29 de abril de 2019.

${ }_{21}$ Depoimento da Diretora da Escola Bruna, concedido à pesquisadora Adayane, em entrevista no decorrer do Estágio Supervisionado II, na cidade Placas, PA, Brasil, no dia 5 de junho de 2019.
} 
(2009), compreender a questão do planejamento de ensino em classes multisseriadas demanda a elaboração de ações didáticas condizentes com as especificidades culturais e identitária das populações que vivem no campo. Além disso, requer docentes com formação adequada e de qualidade, de modo que qualificar o trabalho escolar pressupõe desvinculá-lo de vieses político-partidário.

Tais apontamentos são necessários, porque os discursos em defesa de uma educação específica e diferenciada pautada na diversidade sociocultural dos povos que vivem e/ou trabalham no campo como alternativa, demanda pensar igualmente as políticas de formação dos professores do campo e estreita a vinculação com os modos de produção da vida no campo, sendo condição indispensável ao fortalecimento da identidade camponesa e ao desenvolvimento comunitário, superando o modelo de extensão da escola urbana para a escola do campo rural, ou seja: "[...] deve ser educação, no sentido amplo do processo de formação humana, que constrói referências culturais e políticas para a intervenção das pessoas e dos sujeitos sociais na realidade, visando a uma humanidade mais plena e feliz" (FERNANDES; CERIOLI; CALDART, 2009, p. 23).

Sobre esse aspecto, Munarim e Locks (2012) dão destaque à proposição político-pedagógica da educação do campo que precisa pautar todo o processo formativo e não nas ações educativas que ocorrem dentro da sala de aula, mas precisa se estender para além da escola, pois a aprendizagem e a produção de saberes devem contemplar uma concepção ampla de educação vinculada à cultura e às necessidades das famílias camponesas. Portanto, a escola não pode se contentar somente em cumprir seu papel social e suas finalidades educativas, mas ser concebida como um espaço estratégico de participação, de luta social, de articulação de projetos sociais e de desenvolvimento do campo e de sociedade, na perspectiva de assegurar o direito ao acesso e à qualidade de educação, cumprindo o que determina a LDB - Lei nº 9394/96 e as Diretrizes Operacionais da Educação Básica nas Escolas do Campo (BRASIL, 2002). Em suas palavras:
Esta nova concepção de educação, dentre seus principios, se direciona no sentido da construção da identidade e autonomia das populações do campo. Sustenta o entendimento da relação de complementaridade no binômio campo-cidade. onde uma faceta não vive sem a outra. Desse modo, a educação escolar deve evitar tanto a visão urbanocêntrica quanto o ruralismo. São principios pedagógicos defendidos por esse movimento que as práticas educativas nas escolas devem levar em conta o contexto dos sujeitos do campo, em termos de sua cultura especifica, a maneira de ver e se relacionar com o tempo, o espaço, o meio ambiente e o modo de viver e de organizar o trabalho (MUNARIM: LOCKS, 2012, p. 8).

Destarte, esses dilemas vivenciados quase que permanentemente pelas docentes da escola do campo e que repercutem em suas práticas pedagógicas refletem um contexto já denunciado por Arroyo (2007) quando situa a ausência de preocupações específicas no campo das políticas de formação de professores, tanto no que diz respeito ao currículo, ao livro e material didático, quantoà organização dos tempos escolares, à gestão e à configuração do sistema escolar do campo. Outro ponto que o autor destaca diz respeito às condições precárias de trabalho dos profissionais do magistério no meio rural, revelando o descaso do Poder Público aos diferentes sujeitos coletivos que vivem e trabalham no campo. Em suas palavras: "A falta de politicas específicas de formação de educadoras e educadores e a desestruturação das escolas rurais fazem parte da desconstrução da cultura do campo" (ARROYO, 2007, p. 160).

\section{Considerações finais}

A temática abordada neste estudo nos ajuda a compreender que as políticas de formação de professores das escolas do campo estão articuladas à construção de um projeto de campo que se insira a realidade e seu modo de vida, que constrói e fortalece a identidade dos povos do campo. Defendemos que esta deve se expandir e ser posta em prática; que não seja pensada com uma visão reducionista, e sim na triade campo - políticas públicas de educação, em que se abrangem muito mais questões. 
Para Arroyo (2011, p. 124), o professor que atua na educação do campo tem o direito a receber uma formação pedagógica constante, porém, diferenciada; formações que oportunizem a esse trabalhador desenvolver situações interativas de aprendizagens significativas e socioculturais de modo a contribuir com a melhoria do funcionamento das escolas multisseriadas qualitativamente para assumir "[...] o papel de sujeito do ambiente educativo, criando e recriando as estratégias de formação humana e as relações sociais que o constituem". E, mesmo que seja sua a atribuição do planejamento das aulas voltadas aos estudantes que apresentam identidades socioculturais, idades e niveis de desenvolvimento diferentes de aprendizagem, cognitivo, o professor não é o único responsável. As secretarias de educação e sua equipe técnico-pedagógica também devem responder por essas atividades, por ser competência desse órgão dirigente proporcionar um trabalho coletivo e condições favoráveis para que os professores consigam desenvolver um bom trabalho docente.

Esse direito também dever ser oportunizado aos alunos e comunidade em geral, a terem ciência das melhorias que podem ser ofertadas no próprio local que convivem esses povos do campo. É necessário que líderes comunitários se organizem para cobrar do poder público a oferta de capacitações de acordo com a localidade de atuação desses profissionais. Essas questões são prioritárias e necessárias para ter um modelo educacional mais desenvolvido, para que estejam mais comprometidos, ofertando políticas públicas que favoreçam essas demandas, implementando projetos específicos voltados a real necessidade de cada local, valorizando a identidade e a realidade de cada povo.

Precisamos continuar defendendo a construção de propostas inovadoras que possam amenizar muitos problemas na área da educação do campo. Observa-se que devido à falta de oferta de cursos destinados aos professores do campo que contemplem os diversos contextos, provoca o surgimento de inúmeros entraves para esse profissional desenvolver um bom trabalho, afe- tando assim não só a qualidade profissional, mas a aprendizagem dos estudantes do campo. Diante dessa compreensão, acreditamos ser necessário fazer algumas reflexões a respeito das políticas de formação de professores no cenário brasileiro, pois embora percebamos que haja a manifestação de intenções quanto à formação inicial e continuada dos docentes na atualidade, é preciso considerar a importância do papel que os professores desempenham no fenômeno educativo, de modo especial, aqueles que atuam nas escolas do campo, como forma de se ter uma educação efetivamente inclusiva para esses sujeitos.

\section{Referências}

ARROYO, M. G. Políticas de formação de educadores(as) do Campo. Caderno CEDES, v. 27, n. 72, p.157-176. maio/ago. 2007.

ARROYO, M. G. Currículo, território em disputa. Petrópolis: Vozes, 2011.

ARROYO, M. G; CALDART, R. S.; MOLINA, M. C. (org.). Por uma educação do campo. 2. ed. Petrópolis: Vozes, 2009.

BRASIL. Ministério da Educação. Diretrizes Curriculares Nacionais Gerais da Educação Básica. Ministério da Educação. Secretaria de Educação Básica. Diretoria de Currículos e Educação Integral. Brasília: MEC, SEB, DICEI, 2013. p. 514-533.

BRASIL. Decreto $n^{\circ} 7352$, de 5 de novembro de 2010. Dispõe sobre a política de Educação do Campo e o Programa Nacional de Educação na Reforma Agrária (PRONERA). Diário Oficial da União, Brasilia, 5 nov. 2010.

BRASIL. Ministério da Educação. Educação do Campo: diferenças mudando paradigmas. Caderno Secad 2, Brasília, DF. mar. 2007.

BRASIL. Conselho Nacional de Educação Câmara de Educação Básica. Resolução CNE/CEB 1, de 3 de abril de 2002. Estabelece as Diretrizes Operacionais para a Educação Básica nas Escolas do Campo. Diário Oficial da União [da] República Federativa do Brasil, 9 de abril de 2002. Seção 1, p. 32., Brasilia, 9 abr. 2002.

BRASIL. Lei n. 9.394, de 20 de dezembro de 1996. Estabelece as diretrizes e bases da educação nacional. Diário Oficial da União, Poder Legislativo, Brasilia, DF, 23 dez. 1996.

BRASIL. Relatório Final da Pesquisa Nacional de Educação na Reforma Agrária. MEC/INEP, Brasilia, 2005.

IBGE. PNAD: Sintese de Indicadores Sociais. Rio de Janeiro: IBGE, 2006.

BRASIL. Ministério da Educação. Instituto Nacional de Estudos e Pesquisas Educacionais Anísio Teixeira. Panorama da Educação do Campo. Brasilia: MEC/ INEP, 2006 
CALDART, R. S. Licenciatura em Educação do Campo e o projeto formativo: qual o lugar da docência por área? In: MOLINA, M. C; SÁ, L. M. Licenciaturas em Educação do Campo: registros e reflexões a partir das experiências piloto. Belo Horizonte: Autêntica, 2011. Coleção Caminhos da Educação do Campo 5. p. 95-121.

CHIZZOTTI, Antonio. Pesquisa qualitativa em ciências humanas e sociais. Petrópolis, RJ: Vozes, 2006.

FERNANDES, B. M. Diretrizes de uma caminhada. In: ARROYO, M.; CALDART, R. S.; MOLINA, M. C. (org.). Por uma educação do campo. 2. ed. Petrópolis: Vozes, 2006.

FERNANDES, B. M.; CERIOLI, P. R. CALDART, R. S. Primeira Conferência Nacional "Por uma educação básica do campo" texto Preparatório. In: ARROYO, M. G. CALDART, R. S. MOLINA, M. C. (org.). Por uma Educação do Campo. 4 ed. Petrópolis, RJ: Vozes, 2009.

GATTI, Bernadete A; BARRETO, E. S.de S.; ANDRÉ, Marli E. D. Políticas Docentes no Brasil: um estado da arte. Brasilia: UNESCO, 2011

MUNARIM, A., LOCKS, G. A. Educação do Campo: contexto e desafios desta politica pública. Olhar de professor, Ponta Grossa, v. 15, n. 1, p. 77-89, 2012.

MUNARIM, Antônio. Elementos para uma política pública de Educação do Campo. In: MOLINA, Mônica Castagna (org.). Educação do Campo e Pesquisa: questões para reflexão. Brasília: Ministério do Desenvolvimento Agrário, 2006.p. 15-26.

SANTANA, A. F. T. Pensando possibilidades acerca da formação de professores. Educação Por Escrito, Porto Alegre, v. 5, n. 1, p. 30-40, 26 jun. 2014

SAVIANI, D. Formação de professores: aspectos históricos e teóricos do problema no contexto brasileiro. Revista Brasileira de Educação, Campinas, v. 14, n. 40, p. 143-155, jan./abr. 2009.

SHEIBE, Leda. Valorização e formação dos professores para a Educação Básica: questões desafiadoras para um novo Plano Nacional de Educação. Revista Educ. Soc., Campinas, v. 31, n. 112, p. 981-1000, jul./set. 2010. Disponivel em: http://www.cedes.unicamp.br. Acesso em: 20 jan. 2020

TARDIF, M. Saberes Docentes e Desenvolvimento Profissional. 8. ed. Petrópolis: Vozes, 2007.

VEIGA, Ilma Passos; VIANA, Cleide $M^{a}$ Q. Q. Formação de professores: um campo de possibilidades inovadoras. In: SILVA, Edileuza F. da (org.). A escola mudou. Que mude a formação de professores. Campinas: Papirus, 2010.

\section{Irlanda do Socorro de Oliveira Miléo}

Doutora em Educação pela Pontifícia Universidade Católica de São Paulo (PUCSP), em São Paulo, SP, Brasil; mestra em Educação pela Universidade Federal do Pará (UFPA), em Belém, PA, Brasil; professora da Universidade Federal do Pará (UFPA), em Altamira, PA, Brasil.

\section{Marcos Marques Formigosa}

Doutor em Ensino pela Universidade do Vale do Taquari (Univates), em Lajeado, RS, Brasil; mestre em Educação em Clências e Matemáticas pela Universidade Federal do Pará (UFPA), em Belém, PA, Brasil; professor da Universidade Federal do Pará (UFPA), em Altamira, PA, Brasil.

\section{Adayane Silva de Souza}

Licenciada em Educação do Campo (ênfase em Linguagens e Códigos) pela Universidade Federal do Pará (UFPA) em Placas, PA, Brasil. Professora contratada anos iniciais e finais do Ensino Fundamental da Secretaria Municipal de Educação (SEMED), em Placas, PA, Brasil.

\section{Endereços para correspondência}

Irlanda do Socorro de Oliveira Miléo

Universidade Federal do Pará

Rua Cel. José Porfírio, 2515

São Sebatião, 68.372-040

Altamira, PA, Brasil

\section{Marcos Marques Formigosa}

Universidade Federal do Pará

Rua Cel. José Porfírio, 2515

São Sebatião. 68.372-040

Altamira, PA, Brasil

\section{Adayane Silva de Souza}

Secretaria Municipal de Educação

Rua Olavo Bilac s/n

Centro. 95900-000

Placas, PA, Brasil

Os textos deste artigo foram revisados pela Poá Comunicação e submetidos para validação do(s) autor(es) antes da publicação. 